\title{
A purine-rich DNA sequence motif present in SV40 and lymphotropic papovavirus binds a lymphoid- specific factor and contributes to enhancer activity in lymphoid cells
}

\author{
Monica Pettersson and Walter Schaffner \\ Institut für Molekularbiologie II der Universität Zürich, Hönggerberg, CH-8093 Zürich, Switzerland
}

\begin{abstract}
The enhancer of simian virus $\mathbf{4 0}$ ( $\mathrm{SV40}$ ) is active in a wide variety of tissues and hosts and thus has been called a general enhancer. Previous work has established that this region contains a number of subsegments, each with a different cell type specificity. By analyzing enhancer deletion mutants of SV40 with a restricted cell type specificity, we have identified a purine-rich DNA motif ( $\mathrm{Pu}$ box) that is essential for activity of the mutant enhancer in lymphoid cells and also obtained evidence for an independent element that confers activity in kidney CV-1 cells. The Pu box element is positively regulated since binding of a cognate factor(s) was only observed in lymphoid cell extracts. The Pu box is also present in the 63-bp enhancer repeat of lymphotropic papovavirus (LPV), and competition experiments show that the SV40 and LPV sequences bind the same factor(s). Thus, the Pu box is likely to be a major determinant of the lymphotropic host range of LPV. In SV40, however, the $\mathrm{Pu}$ box is one of several enhancer elements with different cell specificities. We suggest that such an arrangement reflects a diversification strategy of SV40 to maximize its chance of adaptation to various types of host cells.
\end{abstract}

[Key Words: Lymphotropic papovavirus (LPV); simian virus 40 (SV40); enhancer; cell type-specific gene expression]

Received July 8, 1987; revised version accepted September 1, 1987.

Transcriptional control of eukaryotic gene activity is exerted by cis-acting DNA elements of the promoter-enhancer region. One characteristic of enhancers is the ability to stimulate transcription from remote positions, as was first demonstrated with the simian virus 40 (SV40) enhancer (Banerii et al. 1981; Moreau et al. 1981). Subsequently, similar sequences were described in many other viral genomes and in several cellular genes (for reviews, see Gluzman 1985; Serfling et al. 1985a). Some enhancers have a striking cell type preference, the immunoglobulin heavy-chain gene enhancer being the most thoroughly studied example (for review of IgH enhancer, see Matthias et al. 1987; for viral enhancers, see de Villiers et al. 1982; Kenney et al. 1984; Mosthaf et al. 1985).

Enhancers are composed of multiple sequence motifs that can functionally compensate for one another (de Villiers et al. 1984; Herr and Gluzman 1985; Herr and Clarke 1986; Zenke et al. 1986). Individual elements represent binding sites for transcription factors (for review, see Sassone-Corsi and Borelli 1986) and a complex interplay of cis-acting DNA elements with their cognate factors have been suggested to determine the tissue-specific expression of a given gene.

A genetic selection technique, the enhancer trap assay (Weber et al. 1984), can be used conveniently for the isolation of enhancers. In this functional test, linearized SV40 DNA lacking the essential 72-bp enhancer region is cotransfected with putative enhancer DNA into monkey kidney CV-1 cells. Intracellular ligation/repair processes create recombinant DNA molecules and allow selection of viable viruses carrying a heterologous enhancer. Various enhancers were isolated by this technique (Serfling et al. 1985b and references therein). In the course of these experiments, some transfections were performed in which the linearized SV40 enhancer trap genome was transfected into CV-1 cells without the addition of enhancer DNA. Virus growth was observed in a few cases, and two independent SV40 variants designated SV7.2 and SVFE2 were isolated and characterized. DNA sequence analysis revealed that both mutants had undergone similar rearrangements. A duplication of a DNA segment from the late side of the 72-bp repeats had created an enhancer of sufficient activity to substitute 
for the deleted wild-type enhancer (Weber et al. 1984). A similar duplication variant was reported by Swimmer and Shenk (1984).

We report here that the enhancer activity of the SV40 mutants SV7.2 and SVFE2 is restricted to certain cell types. This is in striking contrast to the SV40 wild-type enhancer, which is known to act in a wide variety of cell types (for review see Serfling et al. 1985a; see also Ondek et al. 1987; Schirm et al. 1987). Two different DNA segments mediate the activity of the enhancer variants in CV-1 cells and lymphoid cells. The lymphoid-specific motif was studied in more detail, and we found that activity in lymphoid cells of a DNA segment containing this motif correlates with in vitro binding to a lymphoid-specific factor.

\section{Results}

The enhancers generated by sequence duplication show cell type specificity

Both viable SV40 mutants (SV7.2 and SVFE2, see Fig. 1) lacking the 72-bp repeats have restored enhancer function by duplication of an adjacent sequence (Weber et al. 1984). The enhancer activity was confirmed by transfections and S1 nuclease analysis. A HindIII fragment containing the rearranged region from SV7.2 was able to stimulate transcription, from a downstream position, of the rabbit $\beta$-globin test gene in CV-1 cells (F. Weber and W. Schaffner, unpubl.) and also in the mouse fibroblast cell line 3T6 (Weber et al. 1984). However, we were surprised to find that the fragment lacked any detectable enhancer activity in HeLa cells.

This prompted us to study the cell type specificity of SV7.2 in more detail. The other SV40 variant, SVFE2, has duplicated a similar sequence, albeit with different junctions. Therefore, SVFE2 was also included in the analysis to examine the possible contribution of the junction sequences to the observed cell type specificity.
We decided to analyze the enhancer activity in a variety of human cell lines, thereby focusing our attention on cell type rather than possible species differences. The cloned enhancer variants were transfected by the DEAEdextran method (Luthman and Magnusson 1983) into eight human cell lines representing a broad spectrum of tissues, and the level of T-antigen expression was determined by immunofluorescent staining. As positive controls, the cloned SV $\Delta 50$ virus, which has a small deletion between positions 268 and 322 but shows cell specificity and growth properties identical to SV40 wild-type virus (Weber et al. 1984), and a recombinant with the enhancer from human cytomegalovirus (SVC4; Boshart et al. 1985) were used. The SV40 enhancer trap plasmid (pET-1) with a deletion of the 72-bp enhancer region was included as a negative control.

The results are summarized in Table 1 and demonstrate that the enhancers of both variants, originally selected for activity in CV-1 monkey cells, show strict cell type specificity. They are both active in the human lymphoid cell lines BJA-B and Molt-4 derived from B and T cells, respectively, but not in any other human cell line investigated. By contrast, the SV $\Delta 50$ recombinant shows a clearly detectable level of $T$-antigen expression in all cell lines tested. The human cytomegalovirus enhancer, known to act in a wide variety of cell types (Boshart et al. 1985; Foecking and Hofstetter 1986), also shows activity that is generally higher than that of SV $\Delta 50$. The fact that SV7.2 and SVFE2 show the same cell type specificity suggests that sequences within the duplicated region itself, rather than the junction between the duplicated segments, contribute to the enhancer activity.

We decided to investigate if the duplicated region works as a bona fide enhancer or if additional sequences are necessary for the activity. Since multiple copies of a short oligonucleotide that contains functional enhancer elements can strongly stimulate transcription /Veldman et al. 1985; Gerster et al. 1987; Ondek et al. 1987;

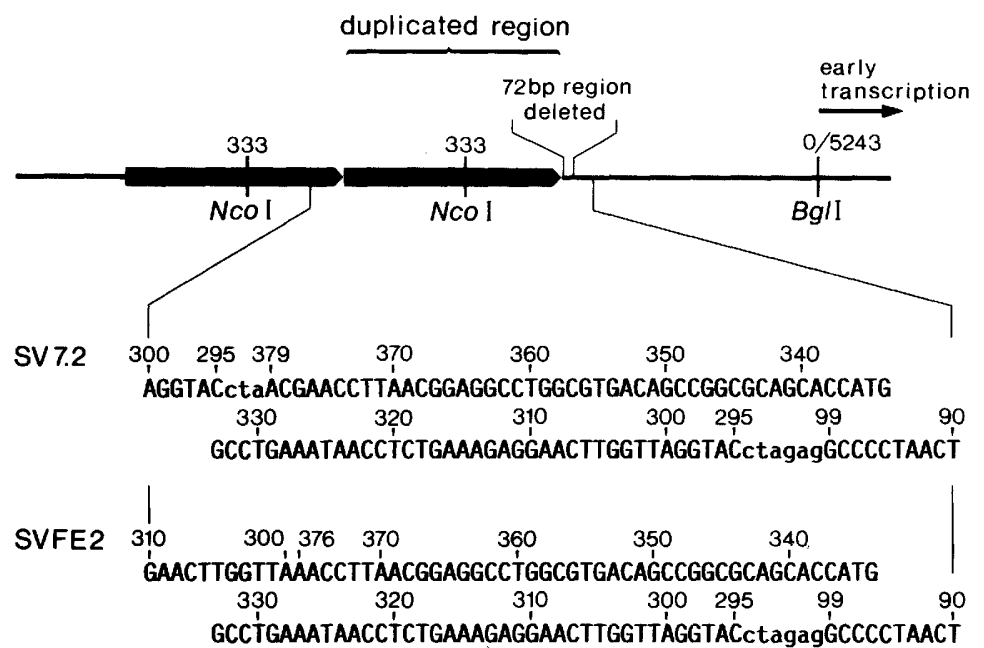

Figure 1. Schematic map of the SV40 duplication variants SV7.2 and SVFE2 and DNA sequence of the duplicated region. The NcoI sites used for initial protein binding studies are indicated. Lower-case letters indicate sequences derived from linkers .used in the construction of the enhancer trap plasmid. The SV40 sequence is numbered according to Tooze (1981). 
Table 1. Activity of the two enhancer variants in different cell lines

\begin{tabular}{|c|c|c|c|c|c|c|}
\hline \multirow{2}{*}{$\begin{array}{l}\text { Cell } \\
\text { Lines }\end{array}$} & \multirow[b]{2}{*}{ Origin } & \multicolumn{5}{|c|}{ Cells positive for $\mathrm{T}$-antigen (\% of total cells) } \\
\hline & & $\overline{\mathrm{ET}}-1$ & FE2 & 7.2 & $\Delta 50$ & $\mathrm{C} 4$ \\
\hline CV-1 & $\begin{array}{l}\text { African Green Monkey, kidney } \\
\text { (epithelium-like) }\end{array}$ & 0 & 1.1 & 1.3 & 1.4 & ND \\
\hline HeLa & $\begin{array}{l}\text { human epitheloid } \\
\text { carcinoma, cervix }\end{array}$ & 0 & 0 & 0 & 7.8 & ND \\
\hline Molt-4 & $\begin{array}{l}\text { human acute lymphoblastic } \\
\text { leukemia (T cell) }\end{array}$ & 0.1 & 1.1 & 1.6 & 2.6 & ND \\
\hline Bowes & human melanoma & 0.3 & 0.3 & 0.3 & 2.4 & 7.3 \\
\hline SK Mel25 & human melanoma & 0 & 0 & 0 & 2.6 & 3.5 \\
\hline MC F7 & $\begin{array}{l}\text { human breast epitheloid } \\
\text { adenocarcinoma }\end{array}$ & 0 & 0 & 0.1 & 1.9 & 9.5 \\
\hline LN-18 & human glioma & 0 & 0 & 0 & 0.6 & 3.5 \\
\hline C1-215 & human glioma & 0 & 0 & 0 & 0.2 & 0.3 \\
\hline BJA-B & $\begin{array}{l}\text { human lymphoblastoid } \\
\text { cell line (B cell) }\end{array}$ & 0.2 & 1.2 & 2.5 & 5.2 & 3.5 \\
\hline
\end{tabular}

Recombinant plasmid $(0.7 \mu \mathrm{g}$ of each/ containing the indicated SV40 genome was mixed with DEAE-dextran and used to transfect the various cell lines. After incubation for $44 \mathrm{hr}$ the enhancer activity was measured by immunofluorescent staining for T-antigen. (ND) Not determined. The same DNA preparations were used for all transfections shown in this table.

Schirm et al. 1987), we chose to synthesize an oligonucleotide comprising the 88 -bp duplicated sequence (SV88wt; Fig. 2A) and to multimerize it. Two or four copies in tandem were inserted in the EcoRI site downstream of a rabbit $\beta$-globin test gene in the plasmid $\mathrm{p} \beta 1 \mathrm{E}$ (Fig. 2B). These constructs were transfected into CV-1 cells using the calcium-phosphate method (Graham and van der Eb 1973; Weber et al. 1984). Enhancer activity was measured in a transient expression assay by S1 nuclease mapping of $\beta$-globin mRNA. Control plasmids included in the analysis were $\mathrm{p} \beta 1 \mathrm{E}$, the globin gene without enhancer (Fig. 2B), and a construct with the
72 -bp repeats from $S V 40$ inserted into $p \beta 1 E$. A truncated form of the test gene under the control of the SV40 enhancer (REF $\Delta$ ) was used as an internal standard for transfection efficiency (Picard and Schaffner 1985). The results shown in Figure $2 \mathrm{C}$ demonstrate that the segment itself contains all the necessary information for enhancer activity. Transcription is enhanced severalfold by two or four copies of the 88-bp segment. An even higher level of activity is seen when the SV40 72-bp repeats are linked to the test gene. Conversely, the enhancerless plasmid $p \beta 1 E$ yields only a very low level of $\beta$ globin mRNA.
A

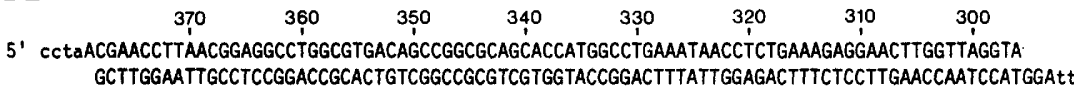

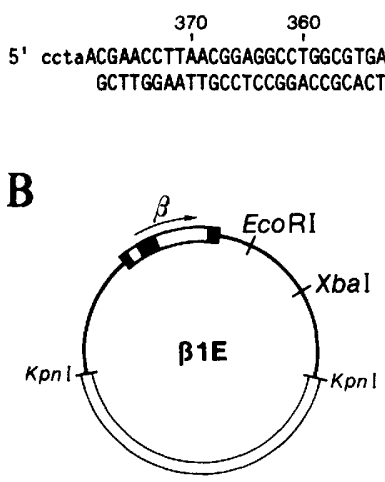

plasmid-DNA

rabbit-DNA

$\stackrel{\text { rabbit-DNA }}{\longrightarrow}$ AGAGGAACTTGGTTÁGGTA TCTCCTTGAACCAATCCATGGAtt

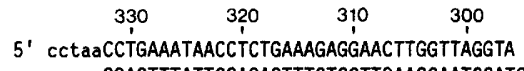$$
\text { GGACTTTATTGGAGACTTTCTCCTTGAACCAATCCATGGATt }
$$

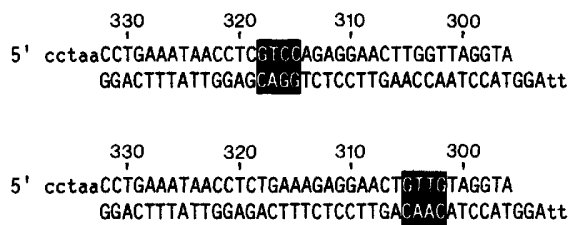

GGACTTTATTGGAGACTTTCTCCTTGACAACATCCATGGAtt
SV88wt

SV88 $\mathrm{pu}^{-}$

SV88wt
SV88pu-
SV42wt
SV42pu-

SV42mmtv-

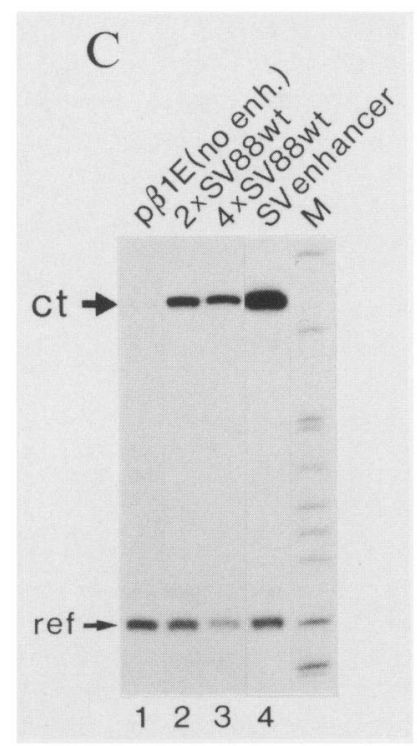

Figure 2. (A) Sequence of the oligonucleotides derived from SV7.2. Mutations introduced are specified by white letters on black background. Nucleotides required to create sticky ends for ligation are printed in lower-case letters. $(B)$ Structure of $p \beta 1 E$, the experimental plasmid used for transient expression of $\beta$-globin mRNA. Fragments were inserted in the EcoRI site. $(C)$ Multiple copies of an 88-bp oligonucleotide act as an enhancer. $\mathrm{p} \beta 1 \mathrm{E}$ recombinants with the indicated inserts were transfected into CV-1 cells using the calcium-phosphate procedure, and levels of $\beta$-globin-specific RNA were determined by S1 nuclease mapping. The size maker (M) was pBR322 cleaved with HpaII. (ct) Correctly initiated transcripts (354 nucleotides); (ref) RNA synthesized from the truncated $\beta$-globin gene REF $\Delta$ (Picard and Schaffner 1985). 


\section{A lymphoid cell-specific factor(s) is interacting with the duplicated sequence}

Interactions between cellular factors and the DNA were studied by bandshift assay (Fried and Crothers 1981; Garner and Rezvin 1981). To this end, the NcoI site within the duplicated segment at SV40 nucleotide position 333 (see Fig. 1) was used to generate fragments $88 \mathrm{bp}$ and $77 \mathrm{bp}$ in length from the two SV40 duplication mutants SV7.2 and SVFE2, respectively. Each labeled fragment was incubated with nuclear extracts from either HeLa cells or the lymphoid cell lines Molt-4 or BJA-B. The DNA-protein complexes were then analyzed by electrophoresis on a low ionic-strength polyacrylamide gel. As shown in Figure 3, the fragments from SV7.2 and SVFE2 behave similarly in this assay. Interestingly, there is a clear difference between permissive and nonpermissive cells (Fig. 3). Exclusively in extracts from Molt-4 and BJA-B cells is a prominent DNA-protein complex formed in addition to two faint faster migrating bands.

The sequences interacting with the factor(s) were determined more precisely by the use of two shorter fragments of 39 and 49 bp obtained by KpnI digestion of the NcoI fragment from SV7.2. Only when the shorter of these two fragments, extending from position 295 to 333 , is incubated with a Molt-4 extract, complexes are formed similar to the whole NcoI fragment (Fig. 3).

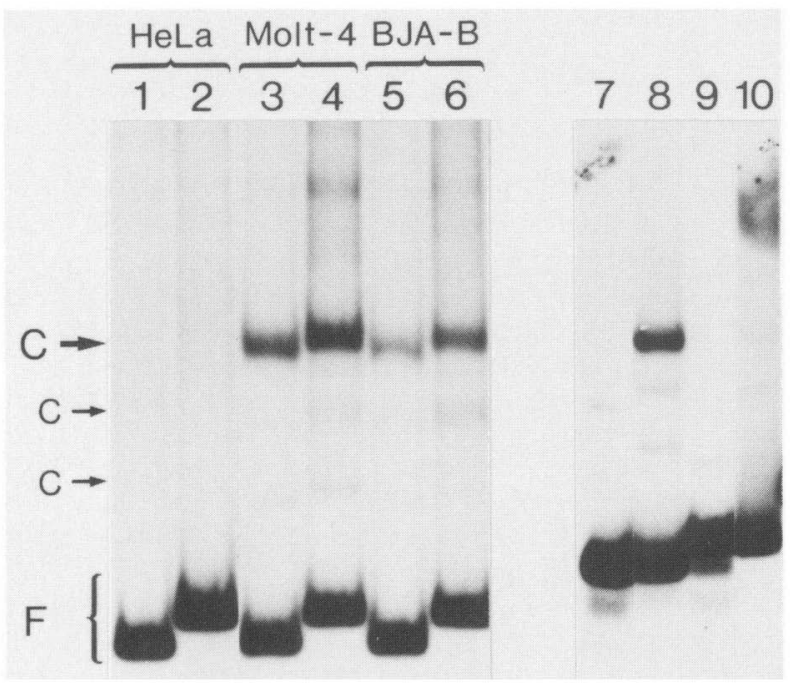

Figure 3. Factors binding to the duplicated sequence are detected in lymphoid cells but not in epitheloid (HeLa) cells. The binding region is located within a 39-bp segment of the duplicated sequence. End-labeled fragments were incubated with cellular extracts and the resulting complexes $(C)$ were separated from the free DNA $(F)$ on a native polyacrylamide gel. The NcoI fragments of $77 \mathrm{bp}$ from SVFE2 (lanes 1,3, and 5) or $88 \mathrm{bp}$ from SV7.2 (lanes 2, 4, and 6) were incubated with a nuclear extract from the indicated cell lines. KpnI digestion of the 88-bp NcoI fragment yields two shorter fragments of 39 bp (lane 7, no extract; lane 8, Molt-4 extract) and 49 bp (lane 9, no extract; lane 10, Molt-4 extract).
Binding of a factor in vitro is consistent with biological activity in vivo

As pointed out previously (Weber et al. 1984), the duplicated fragment has a close homology between positions 296 and 308 to the enhancer region of mouse mammary tumor virus (MMTV) (position - 124 to -136 in the LTR of MMTV; numbering according to Payvar et al. 1983). We considered this sequence to be a likely candidate for mediating the enhancer effect. However, preliminary footprinting experiments indicated DNA-protein interactions in a sequence next to the MMTV homology. The protein-binding region was later determined by bandshifts and methylation interference (see below), and it will henceforth be referred to as the Pu box, since protein binding coincides with a long stretch of purines (nucleotides 308-316). To find out whether either of these two regions, namely, the MMTV homology or the $\mathrm{Pu}$ box, was required for in vivo activity, three doublestranded oligonucleotides $42 \mathrm{bp}$ in length were synthesized. One harbors the wild-type sequence motifs (SV42wt), whereas the other two contain four clustered point mutations either in the MMTV homology $\left(\mathrm{SV} 42 \mathrm{mmtv}^{-}\right)$or in the $\mathrm{Pu}$ box region $\left(\mathrm{SV} 42 \mathrm{pu}^{-}\right.$; Fig. 2A).

The oligonucleotides were multimerized in tandem, cloned downstream of a rabbit $\beta$-globin test gene in the plasmid $\mathrm{p} \beta 1 \mathrm{E}$ (Fig. 2B), and assayed for enhancer activity in the two lymphoid cell lines BJA-B (Fig. 4A, lanes 1-5) and Molt-4 (Fig. 4A, lanes 6-10). Transfections were performed with the DEAE-dextran procedure and enhancer activity quantitated by RNase mapping of transcribed $\beta$-globin mRNA (see Materials and methods). As shown in Figure 4A, four copies of the SV42wt (lanes 2 and 7) and of the SV42 $\mathrm{mmtv}^{-}$(lanes 4 and 9) oligonucleotides enhance transcription from the test gene. No $\beta$-globin transcription above background was detected in the constructs with tandem copies of SV42 $\mathrm{pu}^{-}$where the Pu box is mutated (Fig. 4A, lanes 3 and 8). Identical results were obtained with both cell lines. Therefore, it appears that the Pu box mediates the enhancer effect observed in lymphoid cells. Even though no function was detected for the MMTV homology, we consider it likely that this sequence is active in a cell line not tested here.

When the same constructs were transfected into HeLa cells, none were able to stimulate transcription from the test gene (data not shown). This is in accordance with the inability of the entire duplicated segment of 77 or 88 bp to enhance transcription in HeLa cells.

To investigate whether the activity in vivo correlates with factor binding in vitro, we analyzed the three different oligonucleotides by bandshift assay using a Molt-4 extract. Figure 4B shows that both the wild-type and the SV42mmtv ${ }^{-}$oligonucleotides form the same DNA-protein complex as the natural fragment. By contrast, mutations in the Pu box abolish the formation of the most prominent complex and one of the less prominent faster-migrating complexes. We have not investigated further whether the two complexes that are affected simultaneously are due to interactions with one factor, perhaps an intact and a proteolytically degraded form, or whether the Pu box binds more than one factor. 
Taken together, the fact that mutations within the Pu box eliminate both factor binding and enhancer activity indicates the presence of a cell type-specific transcription factor that binds to the $\mathrm{Pu}$ box and thereby enhances transcription.

Interestingly, in CV-1 cells the cloned 42-bp oligonucleotides did not elicit any enhancer activity (Fig. 5A). Therefore, we tested the hypothesis that activity in CV-1 cells requires an enhancer element independent of the one acting in lymphoid cells. An 88-bp oligonucleotide that corresponds to the duplicated fragment but contains a mutated binding site for the lymphoid-specific factor was synthesized $\left(\mathrm{SV} 88 \mathrm{pu}^{-}\right.$; Fig. $\left.2 \mathrm{~A}\right)$ and cloned in $\mathrm{p} \beta 1 \mathrm{E}$. Transfection of this recombinant revealed that there is indeed an independent enhancer segment acting in monkey kidney cells; two or four copies

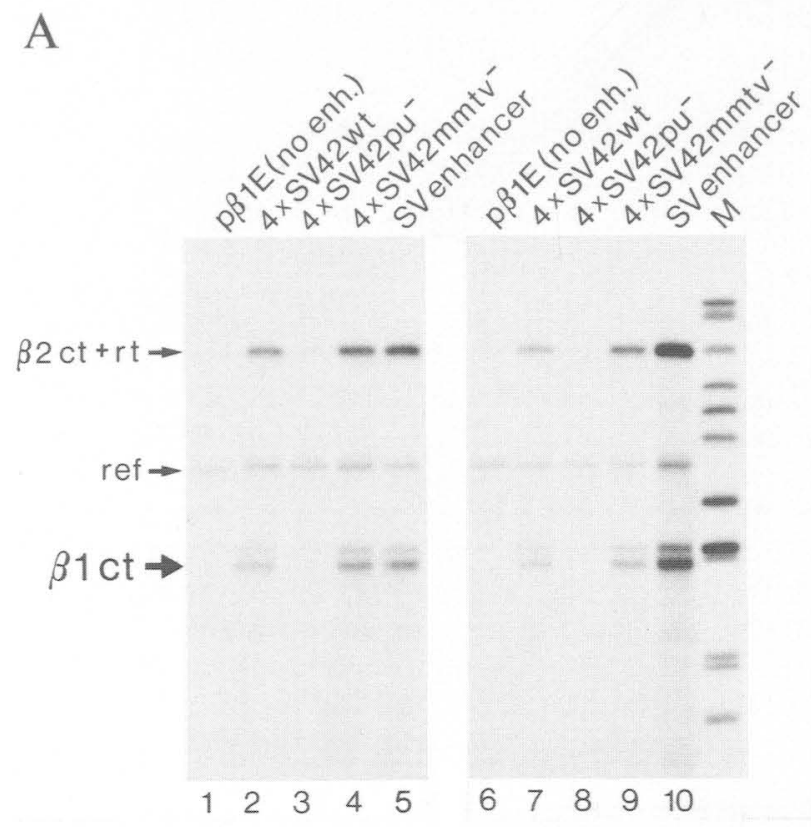

B

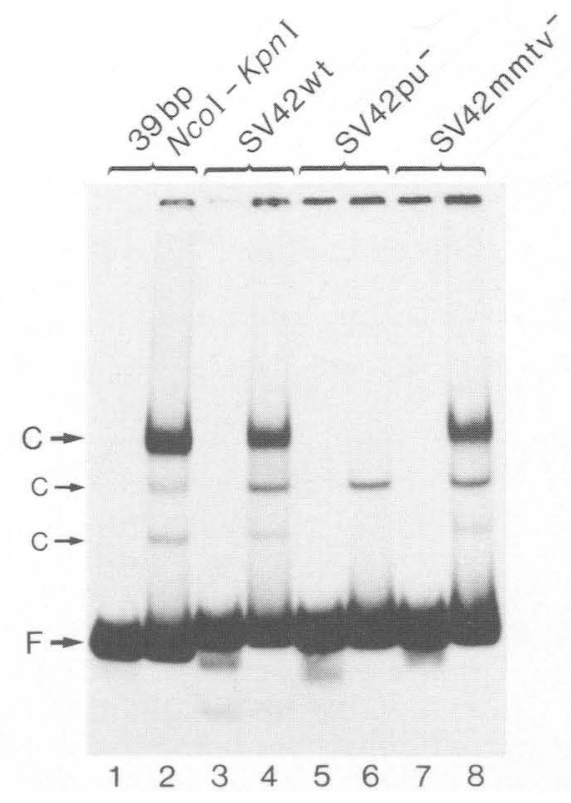

of SV88pu- cloned in the plasmid $\mathrm{p} \beta 1 \mathrm{E}$ yield levels of $\beta$-globin mRNA equal to the wild-type sequence when transfected into CV-1 cells (Fig. 5B). In contrast, only the wild-type sequence of these 88-bp oligonucleotides stimulates transcription in BJA-B cells, whereas tandem copies of SV88pu- show no activity in the lymphoid cell line (Fig. 5C). Thus, the duplicated segment harbors two different elements that are acting independently to give enhancer activity in BJA-B and CV-1 cells. The sequence motif acting in CV-1 kidney cells (tentatively designated KID box/ has not yet been characterized and analyzed for binding of factor(s). Preliminary experiments indicate that the crucial sequence is located around position 330 , since mutations in this region within a dimer of SV88 $\mathrm{pu}^{-}$reduce transcription in CV-1 cells /data not shown). Characterization of this element is in progress.

\section{Specific protein contacts with a purine cluster on one strand}

To determine intimate contact points between the $\mathrm{Pu}$ box and the lymphoid-specific factor, we used the methylation interference procedure (Siebenlist and Gilbert 1980). Both strands of the SV42wt oligonucleotide were partially methylated with dimethylsulfate (DMS). This reagent methylates the $\mathrm{N} 7$ position of guanines and the $\mathrm{N} 3$ position of adenines in the major and minor grooves, respectively. Guanines are more extensively methylated than adenines; therefore, most of the breaks in the DNA backbone occur at guanine residues. Methylated DNA was incubated with an extract from BJA-B cells and the complexed form separated from the free form on a native polyacrylamide gel. Both bands were retrieved from the gel and eluted. If any of the methyl groups interfere with binding of a specific protein, that DNA molecule will be selectively underrepresented in the complexed form rel-

Figure 4. Mutations engineered in the Pu box affect both the ability to enhance transcription in lymphoid cells and the potential to bind lymphoid-specific factor(s) in vitro. The in vivo result is shown in $A$. Four copies in tandem of the different 42-bp-long oligonucleotides were cloned in $\mathrm{p} \beta 1 \mathrm{E}$ and transfected into the lymphoid cell lines BJA-B (lanes 1-5) and Molt-4 (lanes $6-10$ ), and the cytoplasmic $\beta$-globin RNA was quantitated by RNase mapping. Correctly initiated transcripts yield two protected fragments with the SP6 RNA polymerase-generated probe used. $\beta 1 c t$ represents the first exon and directly reflects the activity of the enhancer. The band designated $\beta 2 c t+r t$ mainly represents the second exon in correctly initiated transcripts. In addition, some read-through transcripts initiated further upstream and spliced to the second exon are also contributing to this band. (ref) Transcription from the internal standard gene (Picard and Schaffner 1985). Recombinants with the following inserts were transfected to the different cell lines: (lanes 1 and 6) no insert; (lanes 2 and 7) SV42wt; (lanes 3 and 8) SV42pu-; (lanes 4 and 9) SV42 $\mathrm{mmtv}^{-}$; (lanes 5 and 10) 72-bp enhancer region. (Lane $M$ ) Size marker (pBR322 cleaved with HpaII). A bandshift experiment with the 39-bp natural NcoIKpnI fragment from SV7.2 and the synthesized 42-bp oligonucleotides is shown in $B$. Binding reactions were carried out with $5 \mu \mathrm{g}$ of a nuclear extract derived from Molt -4 cells. The order of the fragments is indicated above the lanes. Lanes with odd numbers show the free fragment in the absence of extract. 


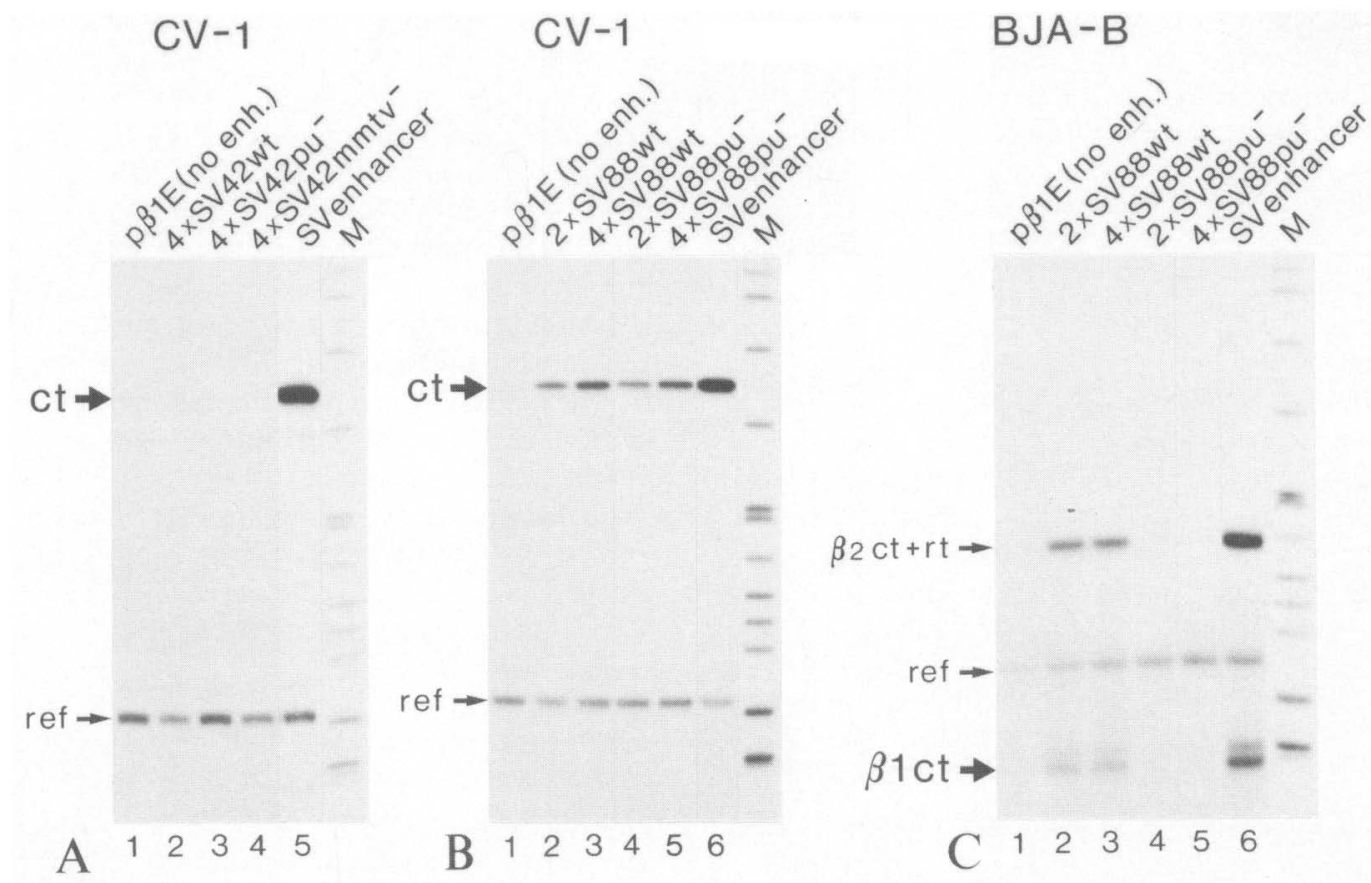

Figure 5. Different enhancer elements are acting in BJA-B and CV-1 cells. (A) Enhancer effect in CV-1 cells of four copies of the 42-bp oligonucleotides. The same recombinants as shown in Fig. 4A were tested and $\beta$-globin transcripts were quantitated by $\mathrm{S} 1$ nuclease mapping. $(B, C)$ Multiple copies of the 88 -bp oligonucleotides were cloned in $\mathrm{p} \beta 1 \mathrm{E}$, and the same set of recombinants was transfected into CV-1 cells $(B \mid$ and BJA-B cells $\langle C|$. The transfected $p \beta 1 \mathrm{E}$ recombinants are indicated above each lane. The ability to enhance transcription was determined by $\mathrm{S} 1$ analysis (CV-1 cells) or RNase mapping (BJA-B cells). (ct, ref, $\beta 1 \mathrm{ct}, \beta 2 \mathrm{ct}+\mathrm{rt}$, and marker) See legends to Figs. $2 \mathrm{C}$ and $4 \mathrm{~A}$.

ative to the unbound DNA. This difference is revealed by a missing band in the G/A ladder after cleavage of the DNA backbone by alkaline treatment and further gel fractionation. We detected protein interactions only with the long stretch of purines on the late strand of SV42wt. As seen in Figure 6A, lanes 4 and 5, methylation of nine individual guanines or adenines (positions $308-316$ ) causes underrepresentation of these molecules in the complex. Of the nine purines, the two adenines at positions 315 and 316 are mutated in SV42pu ${ }^{-}$(see Fig. $6 \mathrm{~B})$. The other two base pairs changed in the $\mathrm{Pu}$ box $\mathrm{mu}$ tants may also be of functional importance, although no protein interactions could be detected with the methylation interference assay (see Discussion).

\section{A sequence related to the lymphoid-specific motif is found in the regulatory region of LPV}

A computer search revealed a perfect homology of $12 \mathrm{bp}$ between the $\mathrm{Pu}$ box and a region within a 63-bp repeat present in the regulatory region of lymphotropic papovavirus (LPV), a primate virus isolated by zur Hausen and Gissmann (1979). To investigate the relevance of this sequence homology, a 31-bp oligonucleotide derived from the LPV genome was synthesized (Fig. 7A). The sequence corresponds to nucleotides 240-270, 303-333, and $481-511$ in the LPV strain K38, which has three 63-bp repeats (Pawlita et al. 1985).

Competition experiments were performed using an excess of unlabeled fragments in the bandshift assay. As shown in Figure $7 \mathrm{~B}$, the LPV sequence prevents the binding of the factor from the BJA-B extract to the SV42wt oligonucleotide with the same efficiency as to the SV40 sequence itself, demonstrating the binding of the same factor to the different enhancers. The same results were obtained in the reciprocal experiment where the labeled LPV oligonucleotide was mixed with the extract and increasing amounts of unlabeled SV42wt oligonucleotide were added (Fig. 7C).

Also shown in Figure 7, B and C, are competitions performed with the oligonucleotide SV42 $\mathrm{pu}^{-}$. Though the mutant oligonucleotide SV42pu- shows no biological activity (Fig. 4A), it still binds the factor with low affinity since a large excess of the mutated oligonucleotide acts as a weak competitor for protein binding.

Similar to the finding with the SV40 Pu box oligonucleotide, we note that there is a qualitative difference in factor binding in HeLa (Fig. 7C, lane 2) and BJA-B (Fig. 7C, lane 3) extracts to the LPV sequence. Only the lymphoid extract forms a complex characteristic for the one seen with the SV40 sequence. With the HeLa cell extract, some complexes of higher mobility are formed.

\section{Discussion}

Is positive control of gene activity prevalent in eukaryotes?

Numerous examples of negative gene regulation have been reported for bacterial systems (for review, see 
Miller and Reznikoff 1978). By contrast, it appears that positive regulation of gene activity is prevalent in eukaryotes. This may reflect a difference in the transcrip-

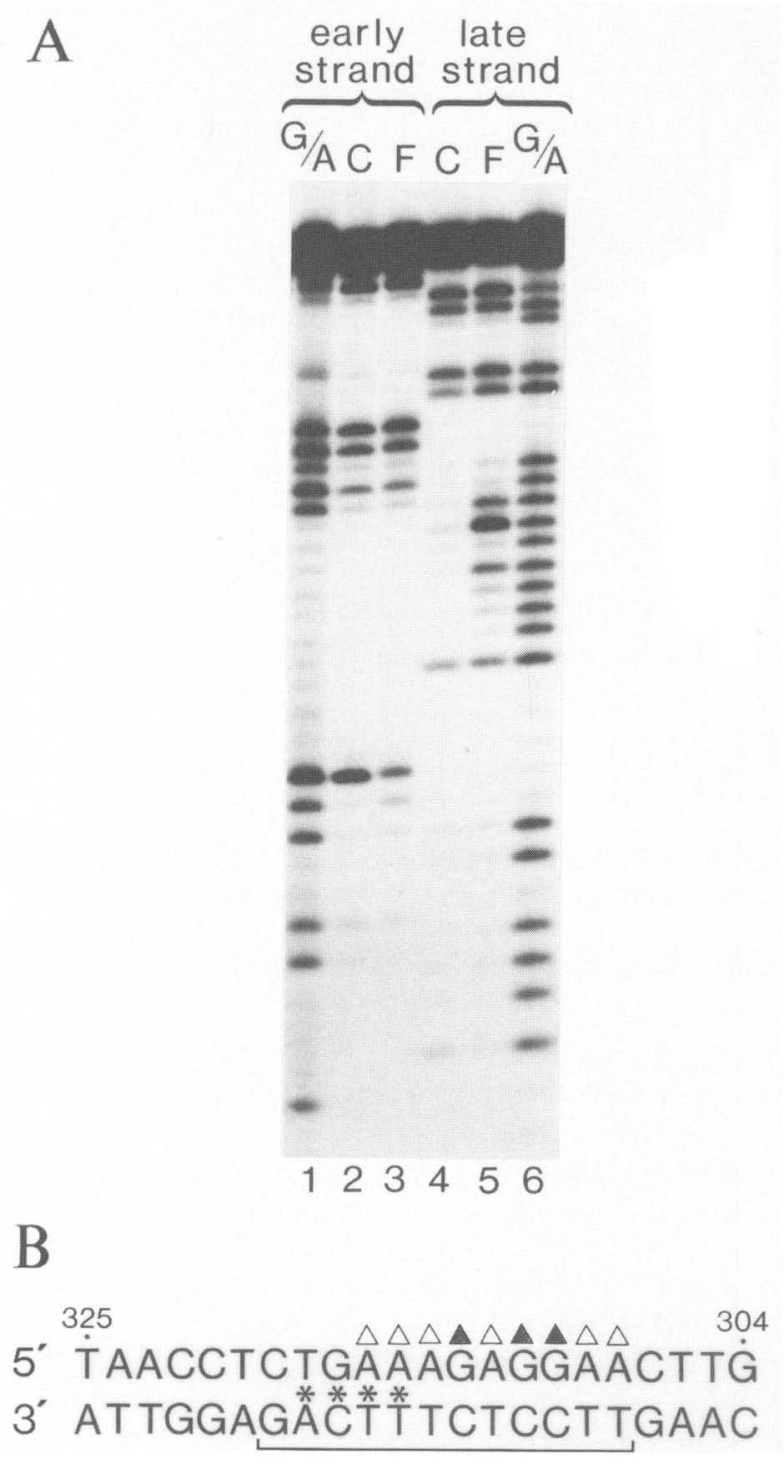

Figure 6. A methylation interference experiment identifies a row of purines as the protein binding region. $(A)$ Both strands of the oligonucleotide SV42wt were end-labeled and analyzed separately after partial methylation. Binding reactions were carried out with a BJA-B extract. Lanes 2 and 4 show the complexed form of DNA from the early and late strand, respectively, analyzed after elution from a preparative polyacrylamide gel. The free fragment from the same binding reactions is shown in lanes 3 (early strand) and 5 (late strand). A G/A sequencing reaction (Maxam and Gilbert 1980) generated from labeled DNA not exposed to proteins was run in parallel (lanes 1 and 6$)$. (B) Summary of the methylation interference data and the mutational analysis of the Pu box. The triangles above the letters show the purines whose methylation interferes with proteinDNA interaction; triangles show strong $(\Delta)$ and weaker $(\Delta)$ interference. $\left({ }^{*}\right)$ Residues that are mutated in SV42pu- and SV88pu ${ }^{-}$and whose integrity is shown to be important for in vivo activity and factor binding (assayed by bandshifts). The bracket marks the perfect homology between SV40 and LPV. tional machinery between prokaryotes and eukaryotes. In prokaryotes, RNA polymerase holoenzyme can recognize a promoter without additional protein factors, whereas in eukaryotes, the polymerase needs to be targeted to the promoter by transcription factors. These bind to specific DNA motifs in the enhancer-promoter region in mammals and to the upstream activating sequences (UASs) in yeast. Omission of one or several of these factors means reduction or even complete loss of transcriptional activity. Therefore, gene activity in eukaryotes can in principle be regulated entirely by controlling the availability of activator proteins.

Some examples of negative regulation of gene activity are also reported in eukaryotes. Apart from the classical autoregulatory mechanism for control of SV40 tumor antigen transcription (for review, see McKnight and Tjian 1986), very few cases have really resulted in an identification of a short binding sequence and a corresponding candidate repressor (Johnson and Herskowitz 1985; Zinn and Maniatis 1986; Barberis et al. 1987).

The finding of a factor interacting with the SV40 lymphoid-specific sequence motif (the Pu box) only in cells where the enhancer element is active argues for positive regulation of transcription with an activator protein present exclusively in permissive cells. This appears to be a straightforward example of positive gene regulation. It remains to be seen whether the gene encoding the $\mathrm{Pu}$ box binding factor is expressed only in lymphoid cells or alternatively, whether posttranslational mechanisms activate the factor when expressed from a constitutively active gene. In other cases the situation is more complex. For example, a conserved decanucleotide motif of consensus ATGCAAATNA /also referred to as octanucleotide) is present in the enhancer-promoter region of both lymphoid-specific immunoglobulin genes and some generally expressed genes such as histone H2B. Two factor variants binding to this motif have been identified, a lymphoid-specific and an ubiquitous one (Landolfi et al. 1986; Staudt et al. 1986; Gerster et al. 1987). Hence, lymphoid-specific or constitutive activity of an individual decanucleotide motif must somehow be decided by an interplay of factors binding to it as well as to neighboring DNA sequences.

\section{Target sequence for the lymphoid-specific transcription factor}

From the methylation interference analysis, we conclude that a stretch of nine purines on one strand of the DNA are protein contact points. The LPV oligonucleotide which competes as efficiently as the wild-type SV40 sequence in the bandshift assay (Fig. $7 \mathrm{~B}, \mathrm{C}$ ) contains the same row of purines. In addition, the homology extends another $3 \mathrm{bp}$ into the region that is mutated in SV42 $\mathrm{pu}^{-}$. We have investigated the relevance of this additional homology and also attempted to find a homolog to the $\mathrm{Pu}$ box in regulatory regions of cellular lymphoid-specific genes. A computer search revealed a related sequence, aTCTGAAAGtGc (nucleotides homologous to the Pu box in capital letters), within the human IgH enhancer (positions 195-206; numbering according to Hayday et 
al. 1984). In addition, the promoter region of the interleukin-2 (IL-2) gene contains conserved, repeated, purine-rich sequences (Fuiita et al. 1986). The seqeunces cAAAGAGGAAa and aGAAAGgAGGAAa are found in the mouse and human IL-2 genes, respectively. Competition experiments were carried out with these sequences (data not shown). The IgH sequence did not interfere at all with protein binding to the $\mathrm{Pu}$ box, which can be explained by the fact that the purine stretch of SV40 shown to be important for protein interactions is not entirely included in the IgH segment. However, even though the complete row of purines is present in the mouse IL-2 promoter, the IL-2 sequence competes with very low efficiency. Consequently, there are further sequences required to form a stable DNA-protein complex than just the purines revealed by methylation interference, most likely the additional $3 \mathrm{bp}$ that are part of the homology to LPV mentioned above.

It should be noted that over the corresponding region of the mouse IgH enhancer, Schlokat et al. (1986) have observed a footprint that was competed by an oligonucleotide from the LPV enhancer containing the Pu box. Since the Pu box is even less homologous to the mouse than the human IgH enhancer, we consider it likely that a factor different from the one described by us was causing the footprint on the mouse IgH enhancer.

\section{Individual cell type-specific sequence motifs in enhancers}

LPV is a member of the polyomavirus group of papovaviruses with a restricted and unique host range. Virus production has only been reported in continuously growing primate cells of B lymphocyte origin (Brade et al. 1981; Takemoto et al. 1982). The enhancer itself has a somewhat wider host range since it is active in several cell lines derived from bone marrow, notably $\mathrm{B}$ and $\mathrm{T}$ cells (Mosthaf et al. 1985). The DNAs of LPV and SV40 cross-hybridize under low stringency conditions (Brade et al. 1983; Kanda et al. 1983), and although LPV is antigenically distinct from SV40, the protein sequences of the two viruses are highly homologous (Pawlita et al. 1985).

The lymphoid-specific enhancer element, called Pu box, is present in one copy in the wild-type SV40 virus and duplicated in our mutants. Although a single copy is sufficient for factor binding, at least two copies are required to create a functional enhancer in the mutants SV7.2 and SVFE2. This may indicate that the factors binding to multiple DNA motifs cooperate to enhance transcription, as discussed by Ondek et al. (1987). In the context of the SV40 wild-type enhancer, the single copy of the $\mathrm{Pu}$ box could well contribute to activity in lymphoid cells in conjunction with the other lymphoid-specific or generally active enhancer elements.

In the regulatory region of LPV the Pu box is present in three copies, two of them in a segment known to harbor enhancer properties (Mosthaf et al. 1985). It is

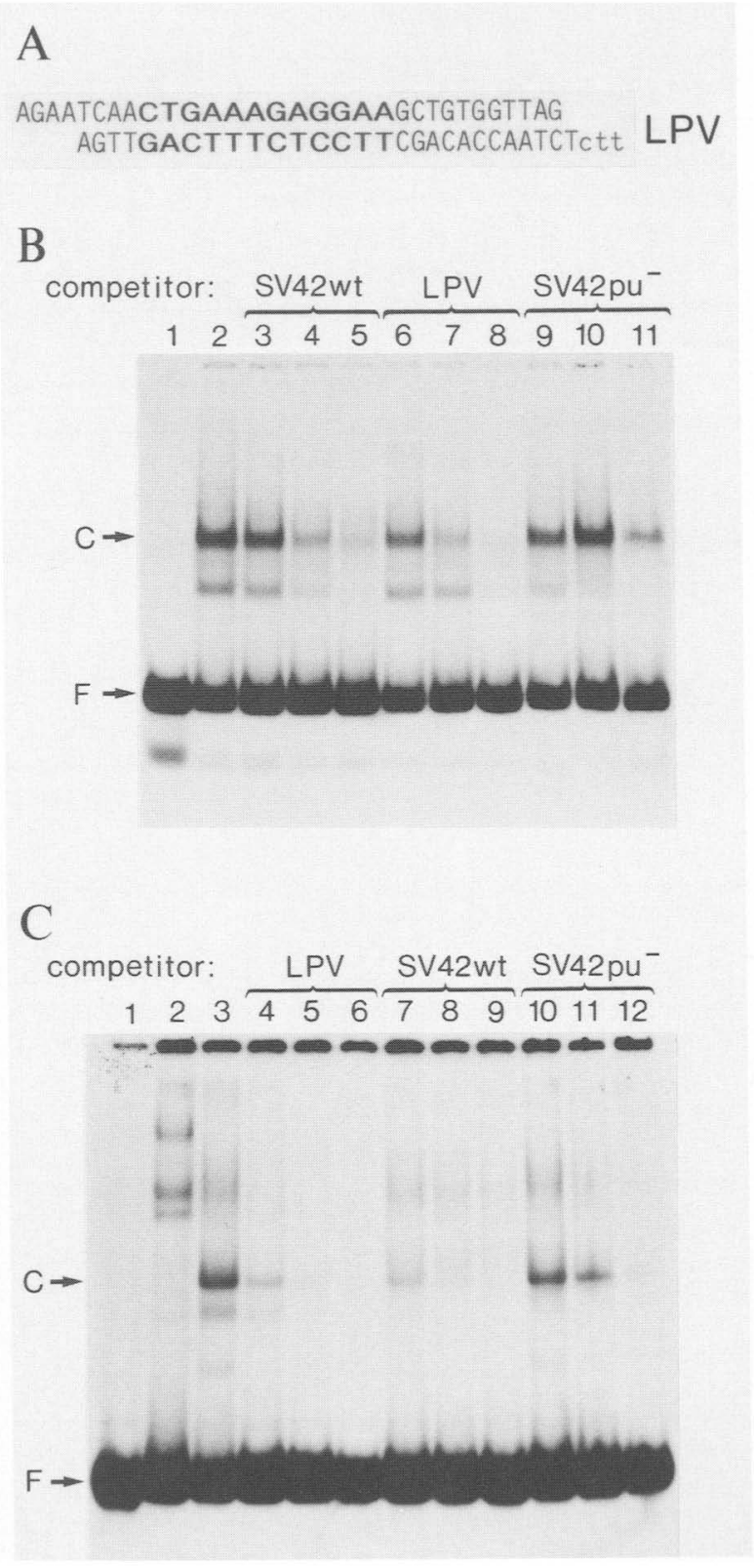

Figure 7. Competition experiments showing that a sequence in the LPV enhancer region binds the same lymphoid-specific factor(s) as the $\mathrm{Pu}$ box of SV40. (A) Sequence of the oligonucleotide derived from the LPV genome (see text for positions of nucleotides). The stretch of $12 \mathrm{bp}$ conserved between SV40 and LPV is indicated in boldface letters. The lower-case letters in one $5^{\prime}$ overhang indicate nucleotides introduced to make multimerization possible. $(B)$ The end-labeled SV42wt oligonucleotide was incubated in a BJA-B extract in the presence of 10 -fold (lanes 3, 6, and 9), 50-fold (lanes 4, 7, and 10), or 100-fold (lanes 5, 8, and 11) excess of the indicated competitors. (Lane 1) The free fragment in the absence of extract; (lane 2) the fragment shifted in the absence of competitors. $(C)$ Competition for binding to the LPV sequence. Binding reactions were performed in a BJA-B extract with the labeled LPV oligonucleotide in the presence of the unlabeled competitors indicated above the lanes. A 10-fold (lanes 4, 7, and 10), 50-fold (lanes 5, 8, and 11), or 100-fold (lanes 6, 9, and 12) molar excess of the various competitors was added. (Lane 1) The free fragment in the absence of extract; (lane 3) incubation in BJA-B extract without addition of any competitor. Also shown in the figure is the binding pattern emerging when the LPV sequence is incubated with a nuclear extract from HeLa cells (lane 2). 
therefore likely that the lymphoid-specific enhancer motif described in this study is a major determinant of the lymphoid-specific tissue tropism of LPV. This is strongly supported by the finding that factor binding to the SV40 motif and the corresponding LPV sequence is found in lymphoid cells only.

In contrast to LPV, the 72-bp enhancer region of SV40 is active in a wide variety of tissues and hosts and thus has been called a general enhancer (for review, see Serfling et al. 1985a). Previous work has established that this region contains a number of subsegments with different cell type specificities (Ondek et al. 1987; Schirm et al. 1987; see also Fig. 8), at least some of which have been shown to bind to cell type-specific factors ( $\mathrm{Da}$ vidson et al. 1986). This led us to postulate that (1) a particular cell type specificity is characteristic for individual enhancer segments, and (2) enhancers of differing specificity can be assembled from the individual sequence motifs by combining them in different patterns, i.e., the specificity of the entire enhancer is not necessarily the sum of its parts (Schirm et al. 1987). Whereas the former statement is confirmed by additional examples, the evidence for the latter is still weak, and our data show a rather simple picture: The lymphoid-specific $\mathrm{Pu}$ box and the kidney cell-specific sequence work independently, and the specificity of an enhancer containing both elements is a mere addition of the two specificities. The question remains why SV40 contains several enhancer elements with different specificities. We suggest that this reflects a diversification strategy of SV40, and probably other viruses, to maximize the chance of adaptation to various types of host cells.

\section{Materials and methods}

\section{Construction of plasmids}

The oligonucleotides were kinased, annealed, and ligated into multiple unidirectional copies, and the ends were filled in by Klenow polymerase. The pool of multimers was fractionated on a native polyacrylamide gel, and dimers and tetramers were excised and ligated into the EcoRV site of a pUC vector con- taining the polylinker EcoRI-XhoI-EcoRV-XhoI-EcoRI. The EcoRI fragment was inserted into the EcoRI site of $\mathrm{p} \beta 1 \mathrm{E}$, the plasmid used for in vivo studies. This plasmid is identical to pßG (de Villiers et al. 1982), except that the EcoRI site in the third exon is removed, thereby leaving a unique EcoRI site downstream of the gene (Gerster et al. 1987).

\section{Cell growth and transfections}

BJA-B cells were cultured in RPMI-1640 medium (Sigma) containing $10 \%$ fetal calf serum, $100 \mathrm{U} / \mathrm{ml}$ penicillin, and 100 $\mu \mathrm{g} / \mathrm{ml}$ streptomycin. All other cells examined were propagated in Dulbecco's modified Eagle's minimal essential medium (GIBCO) supplemented as above, except for HeLa and CV-1 cells where $2.5 \%$ fetal calf serum and $2.5 \%$ calf serum were used. The cells were split $24 \mathrm{hr}$ before transfection and transfected at approximately $60 \%$ confluency in the case of adhering cells and $2 \times 10^{6} \mathrm{cell} / \mathrm{ml}$ in the case of the lymphoid cells.

Transfections were performed using either the DEAE-dextran method (Luthman and Magnusson 1983), replacing the chloroquine treatment with a DMSO-boost, or the calcium-phosphate coprecipitation technique (Graham and van der Eb 1973) with modifications according to Weber et al. (1984).

\section{Immunofluorescence assay and RNA analysis}

Cells were fixed and stained for T-antigen expression 40-44 hr after transfection as described in Banerii et al. (1981). For cells growing in suspension, the fixation procedure was modified as follows: The cells were washed twice with TBS, resuspended in TBS, and added to a fresh petri dish to which they were adhered after $20 \mathrm{~min}$ at room temperature. The medium was aspirated, the plate was dried completely and then fixed with $70 \%$ (vol/ vol) methanol : $30 \%(\mathrm{vol} / \mathrm{vol})$ acetone as described earlier (Banerji et al. 1981). The total number of cells was calculated by counting cells in five to six areas of $0.145 \mathrm{~mm}^{2}$ each and extrapolated to the $64-\mathrm{mm}^{2}$ area used to count the number of fluorescent cells. Cytoplasmic RNA was isolated $40-44 \mathrm{hr}$ after transfection as described by de Villiers and Schaffner (1983). Removal of residual input plasmid DNA by RNase-free DNase (Picard and Schaffner 1983) was included in the extraction procedure.

S1 nuclease mapping was performed according to Weaver and Weissmann (1979), with a single-stranded DNA probe labeled at the BamHI site (position 480 ) of a $\beta$-globin gene that lacks the first intron (Rusconi and Schaffner 1981).

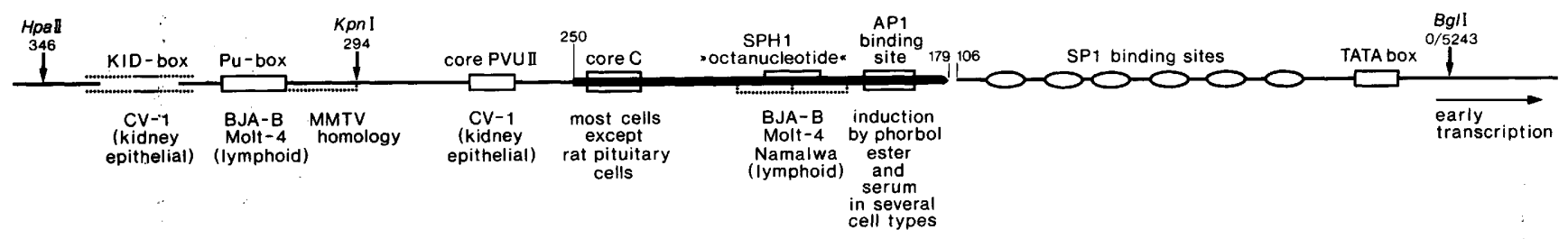

Figure 8. Subsegments of the SV40 enhancer, each showing a particular cell type specificity or inducibility. For simplification, only one copy of the 72-bp repeats is shown (heavy line). The lymphoid-specific Pu box and an element required for CV-1 cell expression (KID box) are described in the text. The MMTV homology is marked by dots, though no function for this sequence was found in the cell lines tested. The corePVUII, SPHI, and coreC regions have been tested as multimerized oligonucleotides of 11,25 , and $20 \mathrm{bp}$, respectively (Schirm et al. 1987). The exact boundaries of the enhancer-active motifs within these short DNA segments were not further delineated. Ondek et al. (1987) have used very similar oligonucleotides from the same three regions, in their case designated A, B, and C, respectively. The APl site confers inducibility by the phorbol ester TPA (Angel et al. 1987). The Spl binding sites are not considered part of the enhancer but rather of the early promoter. The elements shown are certainly not the only ones present in the SV40 enhancer. For example, overlapping with the lymphoid-specific "octanucleotide" motif of the SPHI region are two direct repeats of 9 bp (indicated below the line) that bind another factor (Davidson et al. 1986) and are required for activity in HeLa cells (Zenke et al. 1986). These 9-bp repeats are probably responsible for the activity of the " $B$ " oligonucleotide observed in nonlymphoid cells by Ondek et al. (1987). 
RNA analysis with the SP6 RNA polymerase system (Melton et al. 1984; Picard and Schaffner 1985) was done using a transcript complementary to the unspliced precursor RNA of the $\beta$-globin gene.

\section{Bandshift assay}

Five micrograms of nuclear extracts (prepared as described by Dignam et al. 1983) were incubated with the end-labeled DNA fragments (2-4 fmoles) for $15 \mathrm{~min}$ at room temperature. Incubations were carried out in a final volume of $15 \mu$ l containing $10 \mathrm{~mm}$ HEPES (pH 7.9), $10 \%$ glycerol, $20 \mathrm{~mm} \mathrm{KCl}, 4 \mathrm{~mm} \mathrm{MgCl}$, $10 \mathrm{~mm}$ EDTA, $0.25 \mathrm{~mm}$ DTT, $100 \mu \mathrm{g} / \mathrm{ml} \mathrm{BSA}$, and $4 \mathrm{~mm}$ spermidine. As a competitor to prevent nonspecific binding, $4 \mu \mathrm{g}$ of poly $(\mathrm{dI}-\mathrm{dC}) \cdot$ poly $(\mathrm{dI}-\mathrm{dC})$ (Pharmacia) were added. Samples were loaded on a $4 \%$ polyacrylamide gel (acrylamide : bisacrylamide weight ratio of $29: 1)$ in $6.7 \mathrm{~mm}$ Tris $-\mathrm{HCl}(\mathrm{pH} 7.5), 3.3 \mathrm{~mm}$ $\mathrm{NaAc}$, and $1 \mathrm{~mm}$ EDTA and run at $200 \mathrm{~V}$. In the competition experiments, the appropriate competitor DNA was included in the binding reaction before adding the extract.

\section{Methylation interference}

The end-labeled oligonucleotides were partially methylated with DMS before use in a binding reaction for bandshift that was scaled up 10- to 20-fold with respect to labeled DNA, nonspecific competitor, and extract. After electrophoresis and autoradiography, the complexed and the free fragments were excised from the gel, eluted, purified by DEAE 52 cellulose chromatography, and then ethanol-precipitated. The pellets were resuspended in $20 \mu 1$ of $10 \mathrm{~mm}$ sodium phosphate $(\mathrm{pH} 7.2)$ and 1 mM EDTA, heated to $90^{\circ} \mathrm{C}$ for $15 \mathrm{~min}$ followed by addition of $100 \mu 10.1 \mathrm{M} \mathrm{NaOH}$ and $1 \mathrm{~mm}$ EDTA, and further incubated in $90^{\circ} \mathrm{C}$ for $30 \mathrm{~min}$. This treatment provides both methylated $\mathrm{G}$ and $\mathrm{A}$ residues. The $\mathrm{pH}$ was adjusted to neutral with $1 \mathrm{M}$ Tris, and the samples were precipitated twice with ethanol before analyis on a $15 \%$ denaturing polyacrylamide gel.

\section{Acknowledgments}

We are indebted to Dr. Gotthold Schaffner for synthesizing the oligonucleotides used in this study, to Dr. Frank Weber for preliminary experiments on the cell type specificity of SV7.2, and to our graphic artist Fritz Ochsenbein for preparation of all the figures. We also thank Drs. Dani Schümperli, Meinrad Busslinger, and Charles Weissmann for valuable comments and Heidi Browning for critical reading of the manuscript. This work was supported by the Schweizerischer Nationalfonds and the Kanton Zürich.

\section{References}

Angel, P., M. Imagawa, R. Chiu, B. Stein, R.J. Imbra, H.J. Rahmsdorf, C. Jonat, P. Herrlich, and M. Karin. 1987. Phorbol ester-inducible genes contain a common cis element recognized by a TPA-modulated trans-acting factor. Cell 49: 729-739.

Banerii, J., S. Rusconi, and W. Schaffner. 1981. Expression of a $\beta$-globin gene is enhanced by remote SV40 DNA sequences. Cell 27: 299-308.

Barberis, A., G. Superti-Furga, and M. Busslinger. 1987. Mutually exclusive interaction of the CCAAT-binding factor and of a displacement protein with overlapping sequences of a histone gene promoter. Cell 50: 347-359.

Boshart, M., F. Weber, G. Jahn, K. Dorsch-Häsler, B. Fleckenstein, and W. Schaffner. 1985. A very strong enhancer is located upstream of an immediate early gene of human cytomegalovirus. Cell 41: 521-530.

Brade, L., W. Vogl, L. Gissman, and H. zur Hausen. 1981. Propagation of B-lymphotropoic papovavirus (LPV) in human B- lymphoma cells and characterization of its DNA. Virology 114: 228-235.

Brade, L., N. Mueller-Lantzsch, S. Kaiser, and M. Scharrer. 1983. Biochemical studies on structural and nonstructural proteins of the African green monkey B-lymphotropic papovavirus (LPV). Virology 127: 469-474.

Davidson, I., C. Fromental, P. Augereau, A. Wildeman, M. Zenke, and P. Chambon. 1986. Cell type-specific protein binding to the enhancer of simian virus 40 in nuclear extracts. Nature 323: 544-548.

de Villiers, J. and W. Schaffner. 1983. Transcriptional "enhancers" from papovaviruses as components of eukaryotic expression vectors. In Techniques in the life sciences. B5. Nucleic acid biochemistry (ed. R.A. Flavell), B507/1-B507/ 20. Elsevier, Ireland.

de Villiers, J., L. Olson, C. Tyndall, and W. Schaffner. 1982. Transcriptional "enhancer" from SV40 and polyoma virus show a cell type preference. Nucleic Acids Res. 10: 79657976.

de Villiers, J., W. Schaffner, C. Tyndall, S. Lupton, and R. Kamen. 1984. Polyoma virus DNA replication requires an enhancer. Nature 312: 242-246.

Dignam, J.D., R.M. Lebovitz, and R.G. Roeder. 1983. Accurate transcription initiation by RNA polymerase II in a soluble extract from isolated mammalian nuclei. Nucleic Acids Res. 11: $1475-1489$.

Foecking, M.K. and H. Hofstetter. 1986. Powerful and versatile enhancer-promoter unit for mammalian expression vectors. Gene 45: 101-105.

Fried, M. and D.M. Crothers. 1981. Equilibria and kinetics of lac repressor-operator interactions by polyacrylamide gel electrophoresis. Nucleic Acids Res. 9: 6505-6525.

Fujita, T., H. Shibuya, T. Ohashi, K. Yamanishi, and T. Taniguchi. 1986. Regulation of human interleukin-2 gene: Functional DNA sequences in the 5' flanking region for the gene expression in activated T lymphocytes. Cell 46: 401-407.

Garner, M.M. and A. Revzin. 1981. A gel electrophoresis method for quantifying the binding of proteins to specific DNA regions: Application to components of the Escherichia coli lactose operon regulatory system. Nucleic Acids Res. 9: 3047-3060.

Gerster, T., P. Matthias, M. Thali, J. Jiricny, and W. Schaffner. 1987. Cell type-specificity elements of the immunoglobulin heavy chain gene enhancer. EMBO J.6: 1323-1330.

Gluzman, Y., ed. 1985. Eukaryotic transcription: The role of cis-and trans-acting elements in initiation. In Current Communications in Molecular Biology. Cold Spring Harbor Laboratory, Cold Spring Harbor, New York.

Graham, F.L. and A.J. van der Eb. 1973. A new technique for the assay of infectivity of human adenovirus 5 DNA. Virology 52: 456-467.

Hayday, A.C., S.D. Gillies, H. Saito, C. Wood, K. Wiman, W.S. Hayward, and S. Tonegawa. 1984. Activation of a translocated human c-myc gene by an enhancer in the immunoglobulin heavy-chain locus. Nature 307: 334-340.

Herr, W. and J. Clarke. 1986. The SV40 enhancer is composed of multiple functional elements that can compensate for one another. Cell 45: 461-470.

Herr, W. and Y. Gluzman. 1985. Duplications of a mutated simian virus 40 enhancer restore its activity. Nature 313: $711-714$.

Johnson, A.D. and I. Herskowitz. 1985. A repressor (MATa2 product) and its operator control expression of a set of cell type specific genes in yeast. Cell 42: 237-247.

Kanda, T., K. Yoshiike, and K.K. Takemoto. 1983. Alignment of the genome of monkey B-lymphotropic papovavirus to the 
genomes of simian virus 40 and BK virus. I. Virol. 46: 333336.

Kenney, S., V. Natarajan, D. Strike, G. Khoury, and N.P. Salzman. 1984. JC virus enhancer-promoter active in human brain cells. Science 226: 1337-1339.

Landolfi, N.F., J.D. Capra, and P.W. Tucker. 1986. Interaction of cell-type-specific nuclear proteins with immunoglobulin $\mathrm{V}_{\mathrm{H}}$ promoter region sequences. Nature 323: 548-551.

Luthman, H. and G. Magnusson. 1983. High efficiency polyoma DNA transfection of chloroquine treated cells. Nucleic Acids Res. 11: 1295-1308.

Matthias, P., T. Gerster, D. Bohmann, and W. Schaffner. 1987. Cell-type specificity of transcription: The immunoglobulin heavy chain enhancer as a model system. In Nucleic acids and molecular biology (ed. F. Eckstein and D.M.J. Lilley), pp. 221-240. Springer, Heidelberg.

Maxam, A.M. and W. Gilbert. 1980. Sequencing end-labeled DNA with base-specific chemical cleavages. Methods Enzymol. 65: 499-560.

McKnight, S. and R. Tjian. 1986. Transcriptional selectivity of viral genes in mammalian cells. Cell 46: 795-805.

Melton, D.A., P.A. Krieg, M.R. Rebagliati, T. Maniatis, K. Zinn, and M.R. Green. 1984. Efficient in vitro synthesis of biologically active RNA and RNA hybridization probes from plasmids containing a bacteriophage SP6 promoter. Nucleic Acids Res. 12: 7035-7056.

Miller, J.H. and W.S. Reznikoff, eds. 1978. The operon. Cold Spring Harbor Laboratory, Cold Spring Harbor, New York.

Moreau, P., R. Hen, B. Wasylyk, R. Everett, M.P. Gaub, and P. Chambon. 1981. The SV40 72-base repair repeat has a striking effect on gene expression both in SV40 and other chimeric recombinants. Nucleic Acids Res. 9: 6047-6068.

Mosthaf, L., M. Pawlita, and P. Gruss. 1985. A viral enhancer element specifically active in human haematopoietic cells. Nature 315: 597-600.

Ondek, B., A. Shepard, and W. Herr. 1987. Discrete elements within the SV40 enhancer region display different cell-specific enhancer activities. $E M B O$ I. 6: 1017-1025.

Pawlita, M., A. Clad, and H. zur Hausen. 1985. Complete DNA sequence of lymphotropic papovavirus: Prototype of a new species of the polyomavirus genus. Virology 143: 196-211.

Payvar, F., D. DeFranco, G.L. Firestone, B. Edgar, Ö. Wrange, S. Okret, J.-A. Gustafsson, and K.R. Yamamoto. 1983. Sequence-specific binding of glucocorticoid receptor to MTV DNA at sites within and upstream of the transcribed region. Cell 35: 381-392.

Picard, D. and W. Schaffner. 1983. Correct transcription of a cloned mouse immunoglobulin gene in vivo. Proc. Natl. Acad. Sci. 80: 417-421.

- 1985. Cell-type preference of immunoglobulin kappa and lambda gene promoters. EMBO $J$. 4: 2831-2838.

Rusconi, S. and W. Schaffner. 1981. Transformation of frog embryos with a rabbit $\beta$-globin gene. Proc. Natl. Acad. Sci. 78: $5051-5055$.

Sassone-Corsi, P. and E. Borrelli. 1986. Transcriptional regulation by trans-acting factors. Trends Genet. 2: 215-219.

Schirm, S., J. Jiricny, and W. Schaffner. 1987. The SV40 enhancer can be dissected into multiple segments, each with a different cell type specificity. Genes Dev. 1: 65-74.

Schlokat, U., D. Bohmann, H. Schöler, and P. Gruss. 1986. Nuclear factors binding specific sequences within the immunoglobulin enhancer interact differentially with other enhancer elements. EMBO I. 5: 3251-3258.

Serfling, E., M. Jasin, and W. Schaffner. 1985a. Enhancers and eukaryotic gene transcription. Trends Genet. 1: 224-230.

Serfling, E., A. Lübbe, K. Dorsch-Häsler, and W. Schaffner. 1985b. Metal dependent SV40 viruses containing inducible enhancers from the upstream region of metallothionein genes. EMBO I. 4: 3851-3859.

Siebenlist, U. and W. Gilbert. 1980. Contacts between Escherichia coli RNA polymerase and an early promoter of phage T7. Proc. Natl. Acad. Sci. 77: 122-126.

Staudt, L.M., H. Singh, R. Sen, T. Wirth, P.A. Sharp, and D. Baltimore. 1986. A lymphoid-specific protein binding to the octamer motif of immunoglobulin genes. Nature 323: 640643.

Swimmer, C. and T. Shenk. 1984. A viable simian virus 40 variant that carries a newly generated sequence reiteration in place of the normal duplicated enhancer element. Proc. Natl. Acad. Sci. 81: 6652-6656.

Takemoto, K.K., A. Furuno, K. Kato, and K. Yoshiike. 1982. Biological and biochemical studies of African green monkey lymphotropic papovavirus. J. Virol. 42: 502-509.

Tooze, J., ed. 1981. Molecular biology of tumor viruses. 2nd ed., part 2, revised, DNA tumor viruses. Cold Spring Harbor Laboratory, Cold Spring Harbor, New York.

Veldman, G.M., S. Lupton, and R. Kamen. 1985. Polyomavirus enhancer contains multiple redundant sequence elements that activate both DNA replication and gene expression. Mol. Cell. Biol. 5: 649-658.

Weaver, R.F. and C. Weissmann. 1979. Mapping of RNA by a modification of the Berk-Sharp procedure: The 5' termini of $15 S \beta$-globin mRNA precursor and mature $10 S \beta$-globin mRNA have identical map coordinates. Nucleic Acids Res. 7: 1175-1193

Weber, F., J. de Villiers, and W. Schaffner. 1984. An SV40 "enhancer trap" incorporates exogenous enhancers or generates enhancers from its own sequences. Cell 36: 983-992.

Zenke, M., T. Grundström, H. Matthes, M. Wintzerith, C. Schatz, A. Wildeman, and P. Chambon. 1986. Multiple sequence motifs are involved in SV40 enhancer function. EMBO I. 5: 387-397.

Zinn, K. and T. Maniatis. 1986. Detection of factors that in teract with the human $\beta$-interferon regulatory region in vivo by DNase I footprinting. Cell 45: 611-618.

zur Hausen, H. and L. Gissmann. 1979. Lymphotropic papovavirus isolated from African green monkey and human cells. Med. Microbiol. Immunol. 167: 137-153. 


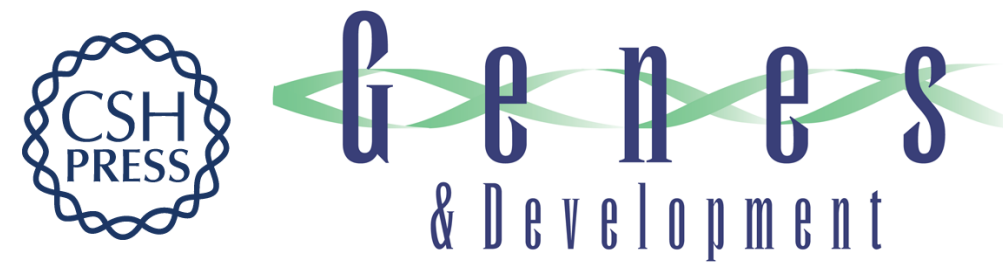

\section{A purine-rich DNA sequence motif present in SV40 and lymphotropic papovavirus binds a lymphoid-specific factor and contributes to enhancer activity in lymphoid cells.}

M Petterson and W Schaffner

Genes Dev. 1987, 1:

Access the most recent version at doi:10.1101/gad.1.9.962

References This article cites 50 articles, 9 of which can be accessed free at:

http://genesdev.cshlp.org/content/1/9/962.full.html\#ref-list-1

License

Email Alerting Receive free email alerts when new articles cite this article - sign up in the box at the top

Service right corner of the article or click here.

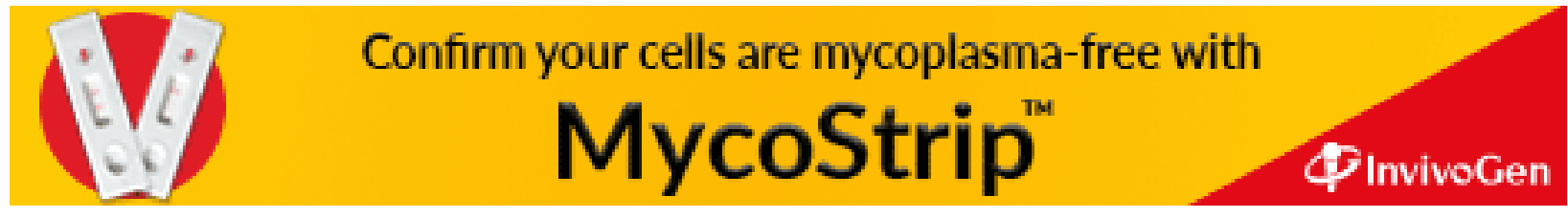

